\title{
Construction and demolition waste generation and management in Lisbon (Portugal)
}

\author{
Aluísio Braz De Melo ${ }^{\mathrm{a}, *}$, Arlindo F. Gonçalves ${ }^{\mathrm{b}}$, Isabel M. Martins ${ }^{\mathrm{b}}$ \\ a Architecture Department, Federal University of Paraíba, C.P. 350, CEP 58.051-900, João Pessoa, PB, Brazil \\ ${ }^{\mathrm{b}}$ Materials Department, National Laboratory for Civil Engineering (LNEC), 1700-066, Lisbon, Portugal
}

\section{A R T I C L E I N F O}

\section{Article history:}

Received 7 January 2010

Received in revised form 3 June 2011

Accepted 17 June 2011

\section{Keywords:}

Waste

Construction

Demolition

Generation

Management

\begin{abstract}
A B S T R A C T
The management of construction and demolition waste (CDW) is essential in the formation, growth and renovation of urban areas. This paper presents part of a study on CDW generation and management in the Lisbon Metropolitan Area (LMA). CDW generation was estimated for 2006 and 2007 based on construction activity and waste load movements. The results revealed that in the municipality of Lisbon, remodeling construction activity prevailed, with CDW generation indicators of 954 t/day and a per capita rate of $0.60 \mathrm{t} / \mathrm{year}$. Both values are above the average for the LMA and its two sub-regions (Greater Lisbon and the Setúbal Peninsula). The installed infrastructure for CDW management identified in the LMA is situated within a maximum distance of about $23 \mathrm{~km}$ from the geometric center of the city of Lisbon. Despite the fact these locations favor the municipality of Lisbon, the occurrence of illegal dumps is still a reality. A notable effort towards environmental education addressing CDW management is under way so as to make involved citizens aware of the recent CDW legislation, Decree-Law Nr. 46/2008, as well as of the problems arising from scenarios of environmental degradation and uncontrolled use of natural resources in the civil construction sector. Policies are outlined aiming to move towards the more judicious management of CDW.
\end{abstract}

(c) 2011 Elsevier B.V. All rights reserved.

\section{Introduction}

In an increasingly urban world, the growth in waste generation, particularly in construction and demolition waste (CDW), has led to serious management problems in cities and countries (Rodriguez et al., 2007). Some studies addressing the economic feasibility of CDW recycling can be found in the literature (Duran et al., 2006; Nunes et al., 2007). Environmental problems resulting from CDW disposal are a cause for concern because of the impacts that illegal disposal sites (which occur routinely) have on cities and their surroundings. This issue has been extensively debated and has stimulated interest in environmentally sustainable solutions. In this context, environmental legislation has become stricter, with a tendency to make waste generators responsible for their own waste, ultimately leading to the adoption of waste minimization and recycling policies (Ekanayake and Ofori, 2004). In the specific case of CDW, due to the importance of the subject, all efforts have been made to create specific legislation that circumvents environmentally undesirable situations such as the uncontrolled disposal of CDW and the over-utilization of natural resources by the civil construction sector.

\footnotetext{
* Corresponding author. Tel.: +55 833216 7115; fax: +55 8332167913.

E-mail address: aluisiobmelo@hotmail.com (A.B. De Melo).
}

Starting in 2008, Portugal adopted a specific legal regimen for CDW management. Previously, CDW management had been subject to the general waste management regimen based on Decree-Law Nr. 178/2006, 5 September, as well as to legislation applicable to special flows, particularly those contained in CDW such as packaging waste. Certain difficulties associated with the application of the provisions of the general regimen to CDW flow led to the drafting of a specific Decree-Law (Decree-Law Nr. 46/2008), which has been in force since 12 June 2008.

This legal framework for managing CDW in Portugal was implemented with the goal of creating legal conditions that promote (among other things) the following goals: reductions in the production of waste and its associated hazards, the screening of waste at its source, recycling, and other forms of CDW re-use. DecreeLaw Nr. 46/2008 also aims to establish a chain of responsibilities to which all involved agents are subject. This legislation includes, in addition to the preparation of CDW Prevention and Management Plans (PMPs) that must accompany project proposals, the approval of technical specifications on the use of CDW for different applications. The above-mentioned Decree-Law accepts, as normative documents, the Technical Specifications on the matter prepared by National Laboratory for Civil Engineering (LNEC) in 2006. The LNEC Specifications are as follows: E 471-2006, Guide for the use of recycled coarse aggregates in hydraulic binder concrete (LNEC, 2006a); E 472-2006, Guide for the production of recycled hot mix asphalt 
(LNEC, 2006b); E 473-2006, Guide for the use of recycled aggregates in unbound pavement layers (LNEC, 2006c); and E 474-2006, Guide for the use of construction and demolition waste in embankments and in base courses of transportation infra-structures (LNEC, 2006d). The minimum requirements applicable to CDW screening and fragmentation facilities in Portugal are included in Annex I of Decree-Law Nr. 46/2008.

The array of Portuguese studies on CDW conducted prior to Decree-Law Nr. 46/2008 demonstrates that the problem had been the object of concern for some time. The following research projects deserve mention:

- European Waste Manual for Above Ground Construction (WAMBUCO), launched in 2002, involving both small- and medium-sized companies from five European countries (Portugal, Denmark, Spain, France and Germany) and which resulted in the first European Waste Manual for Building Construction.

- Recycling of CDW in the context integrated waste management (REAGIR) regarding waste recycling within the framework of integrated waste management, which was jointly subsidized by the European LIFE-Environment Commission/Programme in the 2003-2007 period, was supervised by the Municipality of Montemor-o-Novo in the Alentejo region and had the partnership of the Committee for Supervision and Regional Development of Alentejo (CCDRA), the Technical Superior Institute (IST), College of the Civil Engineering of the Technical University of Lisbon (UTL); the Portuguese Waste Institute (INR - presently Portuguese Agency for Environment - APA) and a prefabricated concrete products company.

As a further indication of the extent of the research done on this subject, PhD theses, MSc dissertations and undergraduate theses on CDW management have been performed within the framework of Portuguese Universities (Carvalho, 2001; Ruivo and Veiga, 2004; Salinas, 2002). Other publications within the scope of technical and scientific events were also prepared prior to Decree-Law $\mathrm{Nr}$. 46/2008, and they were often seen as a forum for debating themes such as the plan for the integrated management of CDW and the methodology for estimating the production of construction waste (Pereira et al., 2004; Santos and Jalali, 2007; Silva and Sousa, 2005a,b)

Nonetheless, as far as CDW management is concerned, even though the legal milestone has been well defined, the environmental situation in cities remains unknown. As stated by Pinto (1999), there is a significant lack of knowledge regarding aspects such as the volumes generated, their corresponding impact, the social costs involved, and the re-use potential. This invariably leads waste managers to only become aware of the seriousness of the situation when they are eventually faced with the inefficiency of their corrective actions.

In the gradual process of transformation towards sustainable CDW management, it is essential to make private initiatives aware that their participation is not only possible but is also increasingly more necessary because generated waste is often re-wasted due to the lack of more appropriate guidance towards the recycling process, i.e., as a result of the absence of proper waste management.

According to Pinto (1999), the success achieved by some CDW recycling plants in terms of both the volume of treated material and the mitigation of environmental impacts is very often attributable to processes based on accurate quantification and on knowledge of the flows and agents involved, i.e., based on a well prepared diagnosis.

Hence, this work addresses part of an extensive study performed at LNEC on construction and demolition waste produced in the municipality of Lisbon-Portugal, having as its reference the period before the application of Decree-Law Nr. 46/2008. In this case study for estimating the production of CDW in the municipality of Lisbon, the data are from 2006 and 2007 and involve a large area, the Lisbon Metropolitan Area (LMA).

The last published study providing a qualitative and quantitative characterization of CDW in Lisbon was one performed by the Municipality in partnership with the INR and the Institute for Applied Science and Technology (ICAT) (Godinho, 1999). The data, which came from the main collection and transportation companies operating in the city, indicated that in 1997 , for a population of 641,449 inhabitants (data from National Institute for Statistical Data - INE), CDW generation within the Municipality of Lisbon was estimated at $680 \mathrm{t} /$ day, and it mainly consisted of inert material. By taking into account the trends of the 1990s, construction activity and the CDW generation were both expected to stabilize until 2002. The study also contained some considerations about possible technical solutions for the treatment and disposal of CDW, such as the installation of a triage unit; the use of clean aggregates for road sub-bases; storage of non-crushable and non-marketable aggregates; the sale of marketable non-aggregate materials; forwarding non-aggregate materials that are not intended for re-use purposes to the urban solid waste system; the implementation of campaigns to raise the awareness of potential customers; the establishment of sufficiently low prices for clean aggregates so as to encourage their intensive use; and lastly, the enforcement of stricter control over illegal waste disposal.

Consequently, the present work performs a comparison with the data from Godinho's study by considering the 10-year interval between the studies.

\section{CDW in Lisbon}

This research stage aimed at identifying the agents involved in the generation, transportation and reception of CDW and to subsequently perform an estimate of CDW generation in the municipality of Lisbon. To identify the agents involved, the study encompassed a larger area, the LMA with its two corresponding sub-regions, Greater Lisbon and the Setúbal Peninsula.

\subsection{Identification of the agents involved in $C D W$ generation, transportation and reception}

In this study, identification of the agents involved in CDW generation in urban areas involved assessing activities related to the construction and remodeling of urban buildings and soil cleaning, excluding waste associated with roadwork and excavation.

To assess the composition of CDW generated in the urban areas of the LMA, the relative proportions coming from new construction and from remodeling were determined. Remodeling work comprises expansion, alteration, rebuilding and demolition.

To characterize construction activity, INE data were collected about the intensity of urban construction over a 10 -year period (1997-2007) regarding formal activity and considering the number (Nr.) and area $\left(\mathrm{m}^{2}\right)$ of completed buildings.

To assess data on the movement of CDW loads, a specific registry of the collection and transportation companies that effectively operate in the city was created based on various information sources:

- consultation of the list of operating agents provided by APA;

- search by name and address of waste collection and transportation companies on internet sites;

- verification of the designations of those companies on containers placed at various work sites in the different neighborhoods of the municipality of Lisbon; 
- confirmation of the addresses of the companies by telephone and subsequent forwarding of inquiries by e-mail or fax;

- consultation of control sheets regarding CDW delivered by transportation companies to other companies in the area identified as final destinations.

In this study, 81 companies were identified as operating within the field of CDW collection and transportation in the Lisbon Metropolitan Area and half of them were contacted to respond to an inquiry about CDW flows: the daily amount of transported waste; the origin of the waste per municipality; the proportion of actions done to collect waste per type of work, new construction versus remodeling; and the final destination of collected waste. From among these companies, 17 responded to the inquiry, which represents $21 \%$ of all such companies operating within the LMA.

A visit to a CDW collection and transportation company allowed the regions with the highest concentration of activity in the urban network of the municipalities included in the LMA to be identified through sampling and through the real time records of the trucks' daily paths on maps.

In order to identify the final destination of CDW declared by the various agents, data were obtained from the corresponding LMA infrastructure, which includes companies within the municipal management of solid waste and companies devoted to the treatment, re-use and disposal of CDW. The main purposes of these consultations were to identify both the CDW flows delivered, per municipality and per user (both municipal and private), and the final destination of waste received.

Regarding the movement of small CDW loads to ecocenters in the region, the main purposes were to obtain quantitative data and to observe on site the reception procedures adopted and the type of vehicles used for waste collection and subsequent transportation to its destination.

Data were also obtained from the municipality of Lisbon and from neighboring cities regarding the procedure adopted for collecting limited amounts of CDW generated in small remodeling jobs by simultaneously identifying their destination. In this case, the data obtained included estimates of both CDW collected from small jobs and of illegal disposal, the latter being confirmed but not located on maps of those cities.

\subsection{Estimating CDW generation: methodology}

As suggested by Pinto (1999) and adopted in that study, CDW generation can be estimated from the following three types of data:

- construction activity as a partial indicator of new construction by taking into account the surface estimates $\left(\mathrm{m}^{2}\right)$ of new completed construction and the waste generation indicator $\left(\mathrm{kg} / \mathrm{m}^{2}\right)$;

- the movement of waste load by collection/transportation companies as a partial indicator of remodeling jobs;

- waste disposal at illegal dumping sites as a partial indicator of illegal disposal.

Special care was taken to avoid overlapping consideration of specific aspects. For instance, in the final aggregation of indicators, the indicator referring to the cleaning of illegal dumps must not be considered if the record of load movement is to be consistent. In fact, in this work, to estimate CDW generation, the indicator referring to illegal disposal was disregarded in the final data compilation because the data provided by the municipalities regarding illegal CDW disposals were not consistent. By contrast, the load movement data from collection/transportation companies proved to be reliable, and hence, it probably includes inappropriate CDW disposal.
Therefore, the construction activity estimates made it possible to establish a partial indicator of CDW generation from new construction, whereas the load movement estimates made it possible to establish a partial indicator of CDW generation from remodeling jobs. Generally, such remodeling jobs, when submitted to the approval of municipal bodies, are seen as small intervention activities that do not represent significant sources of CDW. Hence, as recommended, surface area $\left(\mathrm{m}^{2}\right)$ estimates of remodeling jobs were not used to estimate CDW generation.

\subsubsection{Construction activity}

In order to establish a partial CDW generation indicator for new construction, data on construction activity in Portugal and corresponding regions was used, and it was based on the following:

- the annual average of the actual construction area $\left(\mathrm{m}^{2}\right)$ in the analyzed period (2006 and 2007);

- the adoption of a typical waste generation indicator $\left(\mathrm{kg} / \mathrm{m}^{2}\right)$, as observed at work sites.

In the part of the study referring to the LMA, the data collected regarding construction activity was organized as a function of the number and area of buildings completed on the basis of job type, and they were broken down into two groups: new construction and remodeling. In the method adopted, the data referring to remodeling jobs were disregarded in the partial indicator calculations based on construction activity, and it is assumed that the majority of new construction is formal, i.e., is licensed.

In order to adopt a typical CDW generation indicator $\left(\mathrm{kg} / \mathrm{m}^{2}\right)$, it was necessary to obtain theoretical references based on case studies performed in Portugal in which various CDW generation indicators have been determined per type of construction activity on the basis of new construction for the LMA, its sub-regions and the municipality of Lisbon.

\subsubsection{Load movement}

In accordance with the adopted methodology, it was possible to establish a partial CDW generation indicator for remodeling jobs (which are considered to be informal jobs) on the basis of CDW load movements. In fact, the data available from official bodies represent only part of the construction work and exclude measures of jobs without licensing, which usually correspond to small remodeling jobs performed in existing buildings. Normally, these small jobs are the main source of CDW in urban environments.

Consequently, to estimate the portion of CDW generated by small informal jobs within the LMA, partial data were collected from three sources (adaptation of the Pinto and González recommendations, 2005):

- estimates of CDW collected by collection and transportation companies: data based on the average percentage declared by the company regarding their CDW collection activities from small remodeling jobs;

- estimates of CDW collected by the municipality: data based on its systems for collecting small amounts of CDW, specific to small remodeling jobs;

- estimates of CDW delivered to the ecocenters available in some municipalities in the region.

\section{Generation and management of $\mathrm{CDW}$ in the region}

The municipality of Lisbon, with 499,700 inhabitants (INE, 2007), is the center of a metropolitan area (the LMA) comprising 18 municipalities (Fig. 1) with a total of 2,808,414 inhabitants (INE, 2007). In the municipality of Lisbon, with an area of $84.7 \mathrm{~km}^{2}$ 


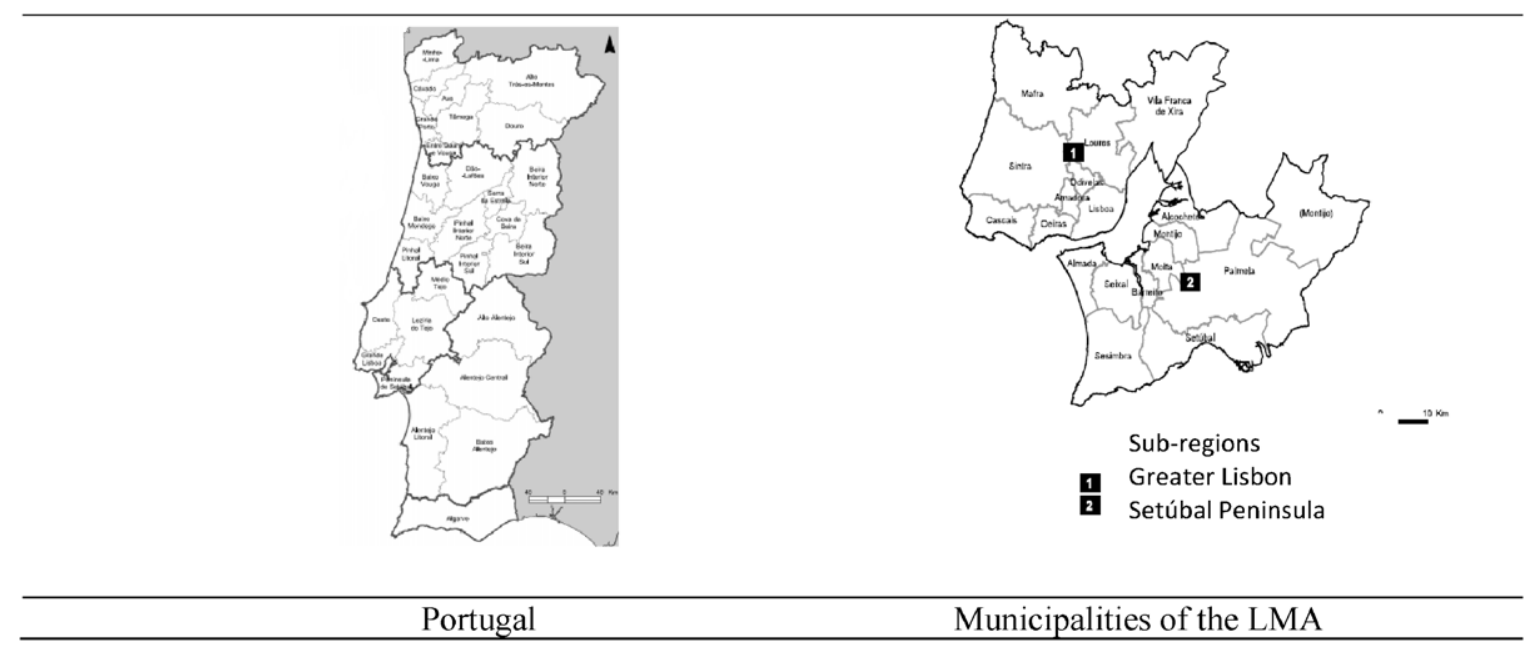

Fig. 1. Location of the LMA and its sub-regions, Greater Lisbon and Setúbal Peninsula, in Portugal (De Melo, 2009).

remodeling work predominates. In 2007, the percentage of jobs related to new building and to the remodeling of existing buildings were $1 \%$ and $99 \%$, respectively (Table 1 ). The opposite situation occurred in other municipalities in the region and with the average values of the sub-regions of the LMA and of the country (INE, 2008).

\subsection{Agents involved in CDW generation, transportation and reception}

The evolution of the intensity of urban construction in Portugal for the 1997-2007 term is presented in Fig. 2. The trend is slightly different from that predicted by Godinho (1999), i.e., there was increasing urban construction activity until 2002, when both the highest number (Nr.) of buildings completed and the largest surface area $\left(\mathrm{m}^{2}\right)$ of completed projects were achieved when taking into account the total number of both new projects and remodeling jobs. Since 2002, a decreasing trend has been observed, which seems to indicate that there has been reduced construction activity in the country, the same being observed for the sub-regions of the LMA.

The seasonal variations in CDW generation can be related to the intensity of construction activity in a specific region. In the case of Portugal, in an analysis of urban construction occurring during the 10-year period from 1997 to 2007 (Fig. 2), two stages of intense construction activity are evident wherein several large demolition, (re)construction and new building projects took place, implying more than average growth in the CDW generated in Portugal: the projects at Parque das Nações for Expo 98 (Lisbon, 1998) and the demolition and construction of new football stadiums, two of them in Lisbon, for the UEFA European Football Championship, Portugal, 2004. In fact, construction activity decreased in the Greater Lis- bon area after 2003 (Fig. 2), when the preparations for the UEFA European Football Championship seem to have come to an end.

A brief analysis of seasonal variations in CDW in line with the construction intensity during that 10 -year period suggests that in the latter part of it (from 2005 on), construction activity tended to stabilize in the Greater Lisbon area (Fig. 2). Therefore, to make it possible to establish a CDW generation estimate for the LMA, in line with the presented methodology, it was chosen to consider an annual average of the quantitative data for a two-year period (2006 and 2007), as this was deemed adequate to minimize seasonal variation effects. Pinto and González (2005) consider the gathering of two-year data (such as the amount of completed projects in $\mathrm{m}^{2}$, CDW removal and illegal disposal) to be sufficient to dilute the construction activity variations due to economic crises and due to seasonal aspects that affect construction (such as a more intense rainfall period).

According to the estimate for the surface area of completed projects (Table 2), the municipality of Lisbon is particularly characterized by very low activity in terms of new construction relative to the total for the Greater Lisbon area. Regarding the proportion by type of project, new construction (17\%) versus remodeling (83\%), similarly to Table 1 , the municipality of Lisbon is characterized by a very high percentage of remodeling work relative to all the other Portuguese regions.

On the basis of data provided by the agents involved, i.e., the companies operating within the area of CDW collection and transportation, it was observed that the movement of loads in the LMA averages $3456 \mathrm{t} /$ day (the estimated value for 81 companies) with the following average source indications: $45.6 \%$ of the collected and transported amount comes from the municipality of Lisbon, and $59.8 \%$ comes from small remodeling jobs. The equipment most used for CDW collection and transportation by companies consists

Table 1

Number of completed buildings (Nr.) by geographic location and type of work: average values for the two-year period 2006-2007 (De Melo, 2009).

\begin{tabular}{|c|c|c|c|c|c|}
\hline \multirow[t]{3}{*}{ Geographic location } & \multicolumn{5}{|c|}{ Type of work } \\
\hline & \multirow{2}{*}{$\begin{array}{l}\text { Total } \\
\mathrm{Nr} .\end{array}$} & \multicolumn{2}{|c|}{ New construction } & \multicolumn{2}{|c|}{ Remodelinga } \\
\hline & & $\mathrm{Nr}$. & $\%$ & Nr. & $\%$ \\
\hline Portugal & 41,480 & 31,970 & 77 & 9510 & 23 \\
\hline LMA & 5717 & 4387 & 77 & 1330 & 23 \\
\hline Greater Lisbon & 3554 & 2344 & 66 & 1210 & 34 \\
\hline Municipality of Lisbon & 355 & 4 & 1 & 351 & 99 \\
\hline Setúbal Peninsula & 2163 & 2043 & 94 & 120 & 6 \\
\hline
\end{tabular}

\footnotetext{
a Includes demolition.
} 


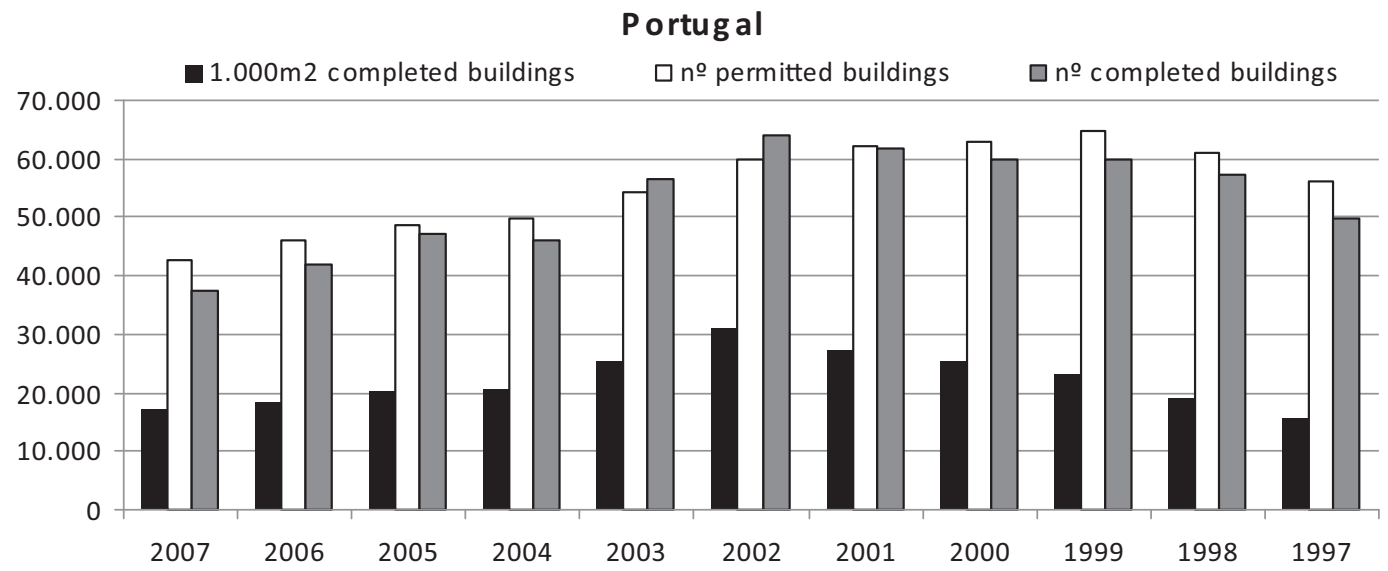

Greater $L$ is bon and $S$ etúbal Peninsula

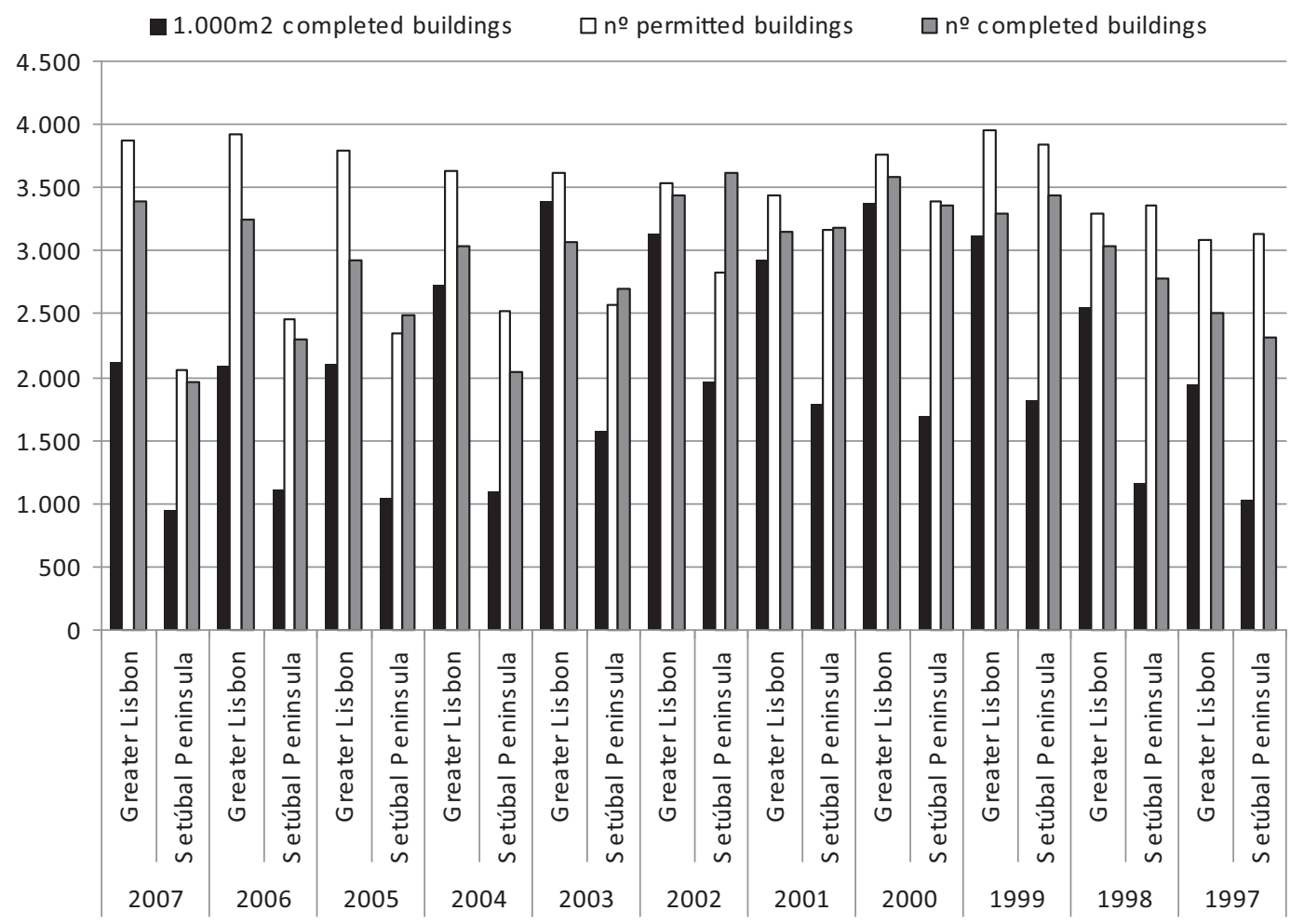

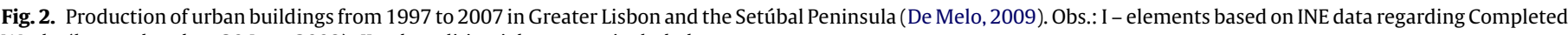
Works (last updated on 30 June 2008); II - demolition jobs are not included.

Table 2

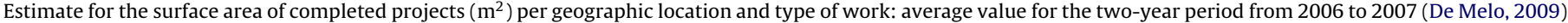

\begin{tabular}{|c|c|c|c|c|c|}
\hline \multirow[t]{3}{*}{ Geographic location } & \multicolumn{5}{|c|}{ Type of work } \\
\hline & \multirow{2}{*}{$\begin{array}{l}\text { Total } \\
\mathrm{m}^{2}\left(10^{3}\right)\end{array}$} & \multicolumn{2}{|c|}{ New construction } & \multicolumn{2}{|c|}{ Remodeling } \\
\hline & & $\mathrm{m}^{2}\left(10^{3}\right)$ & $\%$ & $\mathrm{~m}^{2}\left(10^{3}\right)$ & $\%$ \\
\hline Portugal & 17,885 & 16,163 & 90.4 & 1722 & 9.6 \\
\hline LMA & 3129 & 2819 & 90.1 & 311 & 9.9 \\
\hline Greater Lisbon & 2107 & 1822 & 86 & 286 & 14 \\
\hline Municipality of Lisbon & 99 & 17 & 17 & 82 & 83 \\
\hline Setúbal Peninsula & 1022 & 997 & 98 & 25 & 2 \\
\hline
\end{tabular}

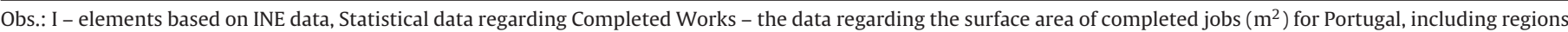

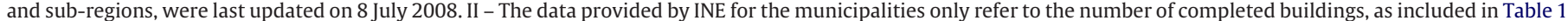

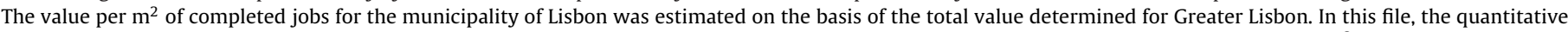

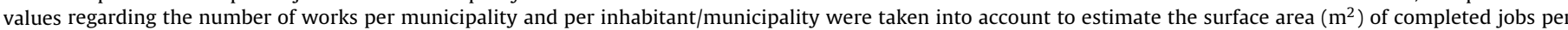
type of work and per municipality. 
Table 3

Agents involved in CDW management as final waste destinations within the LMA (De Melo, 2009).

\begin{tabular}{llll}
\hline \multicolumn{2}{l}{ Agents identified as final CDW destinations } & & \\
\hline Legend (Fig. 4) & Facility & Geographic location \\
\cline { 2 - 3 } & Type & Nr. & \\
\hline Urban solid waste management systems & & \\
L3 and L4 & Landfills & 2 & Setúbal Peninsula \\
E3, E4, E5, E6, E7 and & Ecocenters & 7 & \\
E8 & & & \\
L2 & Landfill & 1 & Greater Lisbon \\
L1 & Landfill & 1 & \\
E1 & Ecocenter & 1 & \\
E2 & Ecocenter & 1 & \\
Treatment, re-use and landfill companies & & \\
C1 & Treatment and & 1 & Greater Lisbon \\
& landfill stations & & \\
C2 & stationsosição & & \\
C3 & Treatment stations & 1 & \\
& Treatment and & 1 & Setúbal Peninsula \\
C4 & landfill stations & & \\
C5 & deposição & & \\
C6 & Aggregate landfill & 1 & \\
\hline & Treatment stations & 1 & \\
\hline & Treatment stations & 1 & \\
\hline
\end{tabular}

of trucks, with containers of $4 \mathrm{~m}^{3}$ and $6 \mathrm{~m}^{3}$ capacity. Regarding the delivery of small amounts of CDW at ecocenters located in the LMA, it has been observed that the vehicles used usually range from small commercial vehicles to passenger vehicles. In the latter case, the vehicle drivers were the ones performing the transfer of CDW to the appropriate site.

As a result of the identification of the agents involved in CDW collection and transportation in the LMA, data have also been obtained from Municipalities about the collection of limited CDW amounts (up to $1 \mathrm{~m}^{3}$ ) generated in small remodeling jobs performed in their own municipalities. For this purpose, equipment such as big bags, containers or even other conditioning means have been used. Generally, this collection system has already been duly defined for more than 12 years in the Regulations on Solid Waste of Municipalities. The dissemination of the system has currently been more consistently achieved at a Municipality institutional site. Some municipalities accept higher limits for the total amount of waste to be collected per job, up to $5 \mathrm{~m}^{3}$, as the periodicity of collection during the execution of projects is variable, but the final destination is invariably a regional landfill. On the basis of responses to inquiries addressed to Municipalities, it is assumed that CDW collection is regularly performed at illegal dumps using equipment such as backhoes and trucks.

The agents involved in the process and identified as the final destination of CDW generated in the LMA consist of three public companies that are part of the urban solid waste management system and six other private companies that are responsible for receiving the waste and for its treatment, re-use and landfill disposal. On the basis of available data, it is assumed that the facilities presented in Table 3 are the infrastructures that, within the LMA, are responsible for receiving, treating and re-using CDW and for disposing of it in landfills. In fact, Table 3 shows that the Setúbal Peninsula is equipped with a larger infrastructure for receiving CDW. Moreover, the two sub-regions have different numbers of ecocenters, with seven in the Setúbal Peninsula and two in Greater Lisbon.

In one of the CDW collection and transportation companies, it was possible to identify, by tracing on maps the daily paths followed by vehicles using a GPS system, regions with higher concentrations of activity within the urban network of the municipalities
Table 4

Theoretical references considered for an average CDW generation indicator $\left(\mathrm{kg} / \mathrm{m}^{2}\right)$ for Portugal (De Melo, 2009).

\begin{tabular}{|c|c|c|}
\hline Indicators & & Source \\
\hline $211 \mathrm{~kg} / \mathrm{m}^{2}$ & $\begin{array}{l}\text { CDW generation by per capita estimate } \\
\text { ( } 325 \mathrm{~kg} / \text { inhab.year), reference year } 1997 \text {, } \\
\text { excluding soil and asphalt, based on the } \\
\text { construction activity in Spain }\end{array}$ & $\begin{array}{l}\text { Symonds } \\
(1999)\end{array}$ \\
\hline $141 \mathrm{~kg} / \mathrm{m}^{2}$ & $\begin{array}{l}\text { CDW production estimate in Portugal } \\
\text { ( } 423 \mathrm{~kg} \text { /inhab.year) reference year } 2002 \text {, } \\
\text { excluding soil and vegetation, based on } \\
\text { studies conducted in Spain in } 2000 \text { by } \\
\text { Institut de Tecnologia de la Construccion } \\
\text { de Catalunya (ITEC) on various projects } \\
\text { over six months, as well as on data } \\
\text { provided by the Municipality of Barreiro } \\
\text { (Portugal) regarding waste generated by } \\
\text { expansion, alteration and rebuilding } \\
\text { projects }\end{array}$ & $\begin{array}{l}\text { Ruivo and } \\
\text { Veiga (2004) }\end{array}$ \\
\hline $122 \mathrm{~kg} / \mathrm{m}^{2}$ & $\begin{array}{l}\text { CDW estimate for Portugal } \\
\text { (199.5 kg/inhab.year), reference year 2007, } \\
\text { excluding soil and asphalt, based on a } \\
\text { sampling procedure that divides projects } \\
\text { by type (demolition, rehabilitation, new } \\
\text { construction), function (housing buildings, } \\
\text { services and public works buildings } \\
\text { [roads]) and age range }\end{array}$ & $\begin{array}{l}\text { Coelho and } \\
\text { Brito (2008) }\end{array}$ \\
\hline $158 \mathrm{~kg} / \mathrm{m}^{2}$ & Average adopted in the present work & \\
\hline
\end{tabular}

integrated in the LMA. ${ }^{1}$ In this case, the same company is simultaneously a final destination for collected waste because it is also responsible for the treatment and landfill of the inert fraction of material. A randomly selected sample consisting of 11 path maps for two typical days of the company's operation using various vehicles indicates that Lisbon is the only municipality present in every path. Moreover, the highest frequency of displacements occurred in the center and northeast regions, Olivais and Sacavém, of the urban network of the municipality of Lisbon. Fig. 3 depicts a map of a typical CDW collection day in which the activity in the central region of the municipality of Lisbon is particularly emphasized (the detailed map on the right side of the figure).

\subsection{Estimates for CDW generation within the LMA}

On the basis of data for new construction (Table 2), and in accordance with the calculation methodology adopted to estimate the amount of CDW generated by this type of work, for each geographic location it was possible to calculate the product of the yearly average new construction $\left(\mathrm{m}^{2}\right)$ in the area by the typical CDW generation indicator as defined for Portugal. In this study, the indicator adopted corresponds to $158 \mathrm{~kg} / \mathrm{m}^{2}$, which is the average value of three case studies (Table 4) considered to be consistent and which are part of an analysis of reference works on this subject.

Table 5 presents the partial CDW generation indicator for new construction, which shows, as far as the municipality of Lisbon is concerned, a low value for this type of construction. In fact, this was expected, considering the low number of new construction projects in an urban area with a high building density in which some of the buildings are quite old. Another interesting aspect refers to the fact that the CDW generation indicator for this type of work for Greater Lisbon (65\%) is almost double the indicator for the Setúbal Peninsula (35\%), with this ratio remaining virtually the same when comparing the number of inhabitants in the two regions.

\footnotetext{
1 After identifying urban areas with higher waste collection activity, the Company plans to create transfer and triage stations (temporary disposal) for CDW and thus streamline the transportation of larger amounts by vehicle to their final destination - the headquarters of the very company, where the treatment and re-use of that waste are performed.
} 


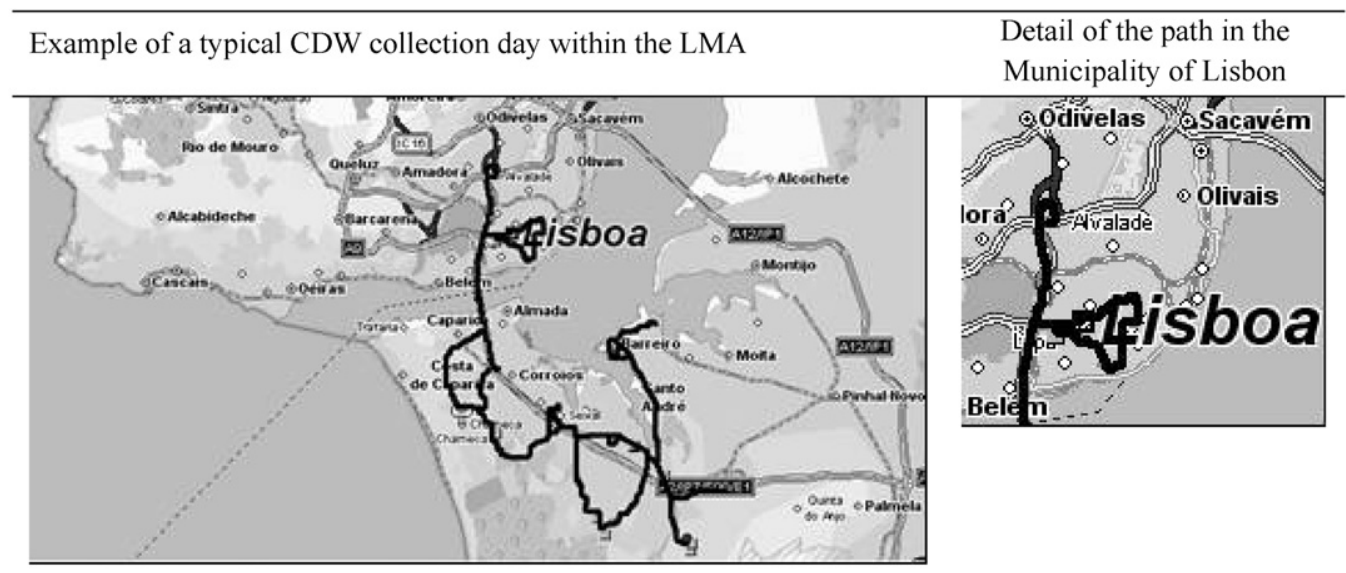

legend: $\quad$ paths of vehicles controlled at the Company's headquarters, on real time, by GPS.

Fig. 3. Map showing an example of the path followed by a company's vehicle on a typical CDW collection route within the LMA (De Melo, 2009).

Table 5

Partial CDW generation indicator for new construction projects per geographic location: average value for the two-year period from 2006 to 2007 (De Melo, 2009).

\begin{tabular}{|c|c|c|c|c|c|c|}
\hline \multirow[t]{3}{*}{ Geographic location } & \multicolumn{2}{|c|}{ Population 2007} & \multicolumn{4}{|c|}{ Data for new building construction (family dwellings and others) } \\
\hline & \multirow[t]{2}{*}{ Inhab. $\left(10^{3}\right)$} & \multirow[t]{2}{*}{$\%$} & \multirow{2}{*}{$\begin{array}{l}\text { Average area } \\
\mathrm{m}^{2}\left(10^{3}\right)\end{array}$} & \multicolumn{3}{|c|}{ Partial CDW generation indicator } \\
\hline & & & & t/year $\left(10^{3}\right)$ & t/day & $\%$ \\
\hline LMA & 2808 & 100 & 2819 & 445 & 1427 & 100 \\
\hline Greater Lisbon & 2026 & 72 & 1822 & 288 & 923 & 65 \\
\hline Municipality of Lisbon & 500 & 18 & 17 & 3 & 9 & 0.6 \\
\hline \multirow[t]{2}{*}{ Setúbal Peninsula } & 783 & 28 & 997 & 157 & 505 & 35 \\
\hline & A & B & $\mathrm{C}$ & $\mathrm{D}$ & E & $\mathrm{F}$ \\
\hline
\end{tabular}

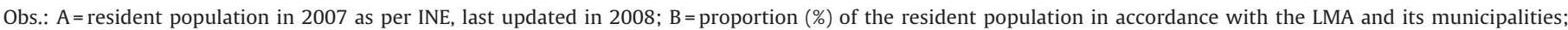

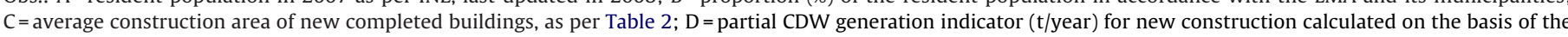

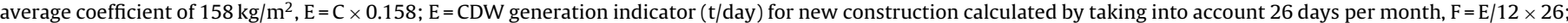
$\mathrm{F}=$ proportion (\%) of CDW generated from new construction in accordance with the LMA and its municipalities.

Table 6 presents data referring to CDW load movements in the LMA that correspond only to collections from remodeling jobs. These values are based on the fact that $59.8 \%$ of the $3.456 \mathrm{t}$ /day of CDW collected and transported by companies comes from small remodeling jobs (2.067 t/day). The same table also presents estimates for CDW collected by other means, municipalities and ecocenters, which should also be added to the amount of CDW generated in small remodeling jobs. This table also shows that the

Table 6

Estimate for CDW generated in remodeling jobs based on movements of CDW loads collected and transported by companies using other means within the LMA: average value for the two-year period from 2006 to 2007 (De Melo, 2009).

\begin{tabular}{|c|c|c|c|c|c|}
\hline \multirow[t]{3}{*}{$\begin{array}{l}\text { Geographic } \\
\text { location }\end{array}$} & \multirow{3}{*}{$\begin{array}{l}\text { Proportion of CDW } \\
\text { collection company } \\
\text { activity per municipality } \\
\%\end{array}$} & \multicolumn{2}{|c|}{$\begin{array}{l}\text { Estimate of CDW collected by } \\
\text { companies }\end{array}$} & \multicolumn{2}{|c|}{$\begin{array}{l}\text { Estimate of CDW collected by } \\
\text { other means }\end{array}$} \\
\hline & & Total & $\begin{array}{l}\text { CDW estimate in } \\
\text { Remodeling Works } \\
\text { (include demolition) 59.8\% }\end{array}$ & $\begin{array}{l}\text { Up to } 1 \mathrm{~m}^{3} \text { collection by } \\
\text { Municipalities }\end{array}$ & $\begin{array}{l}\text { Up to } 1 \mathrm{~m}^{3} \text { voluntary } \\
\text { and free delivery at } \\
\text { Ecocenters }\end{array}$ \\
\hline & & t/day & t/day & t/day & t/day \\
\hline LMA & 100.0 & 3456 & 2067 & 80.98 & 28.33 \\
\hline Greater Lisbon & 83.3 & 2879 & 1722 & 10.96 & 0.03 \\
\hline Municipality of Lisbon & 45.6 & 1577 & 943 & 2.11 & 0.03 \\
\hline \multirow[t]{2}{*}{ Setúbal Peninsula } & 16.7 & 577 & 345 & 70.02 & 28.30 \\
\hline & A & B & $\mathrm{C}$ & $\mathrm{D}$ & $\mathrm{E}$ \\
\hline
\end{tabular}

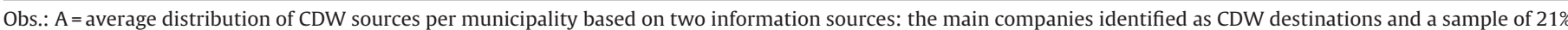

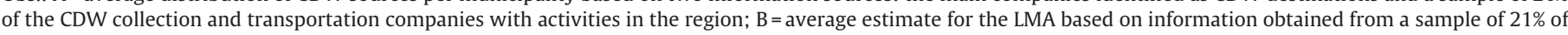

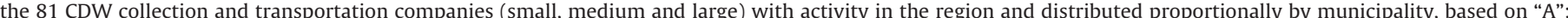

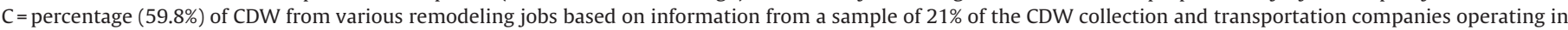

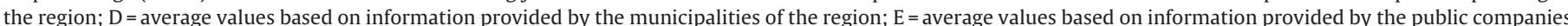

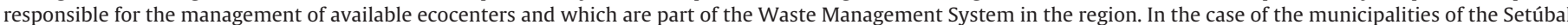

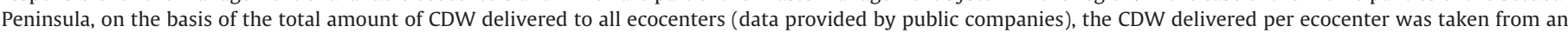

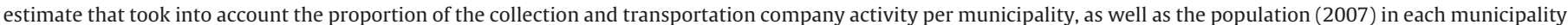


low value for CDW delivered at ecocenter "E1" in the municipality of Lisbon is insignificant when compared to the values for CDW delivered to other ecocenters distributed across the various municipalities of the Setúbal Peninsula. The CDW collection implemented by municipalities is of low importance, and is more defective in Greater Lisbon.

As predicted by the methodology, Table 7 presents a set of data used to estimate CDW load movements resulting from remodeling without taking into account the amount of CDW present in illegal dumps. From this data, it was possible to determine (according to the geographic location) a partial CDW generation indicator (t/day) for remodeling jobs, which were considered in this study to be informal. As expected, in the LMA, the majority of CDW (43\%) is generated in the municipality of Lisbon. Moreover, Greater Lisbon generates more CDW from remodeling (80\%) than does the Setúbal Peninsula (20\%).

The composition of this indicator also demonstrates that CDW flows, both through the collection system implemented by Municipalities and through voluntary and free delivery at ecocenters, are much less when compared to the load movements estimated from CDW collection and transportation companies. This seems to suggest that the infrastructure available to facilitate CDW flows, especially those coming from small remodeling jobs, is not appropriate or even insufficient for the purpose, from the viewpoint of both the spatial distribution and the quantity of delivery points. This is a more serious situation for Greater Lisbon than it is for the Setúbal Peninsula.

Table 8 presents the final CDW generation indicator based on the sum of the partial estimates for both new construction and remodeling. The municipality of Lisbon presents CDW generation equivalent to the group of municipalities within the Setúbal Peninsula: $26 \%$. From the composition of that indicator, it is clear that the estimate for CDW collected in illegal dumps is quite insignificant when compared with the estimates regarding CDW generation in new construction and remodeling, which leads to poor consistency in data. Moreover, reference must be made to the fact that various municipalities did not responded to the inquiry about the data regarding CDW collection at illegal dumps. Indeed, it is likely that the amount of CDW present in illegal dumps is much higher than that presented in Table 8. Moreover, the estimate of CDW present in illegal dumps has probably already been included in the estimates regarding waste loads moved by collection and transportation companies.

Table 9 shows the indicator and the per capita rate of CDW generation for the LMA, its sub-regions and the municipality of Lisbon. A higher average per capita rate occurs for the municipality of Lisbon: 0.60 .

Table 10 compares two CDW generation estimates for the municipality of Lisbon performed within a 10-year interval (Godinho, 1999; De Melo, 2009). It shows that the present estimate for 2007 is approximately $40 \%$ higher than the previous estimate, for 1997, and a more significant difference is observed for the per capita rate, which is partly justified by the present reduction in the population residing in Lisbon.

\subsubsection{Uncertainty analysis of the key factors}

For the uncertainty analysis of the key factors involved in performing the CDW generation estimate, for the present study it is important to underline some aspects anticipated in the adopted methodology, mainly the necessary controls that aim at reducing such uncertainties in the results. The methodology adopted (Pinto and González, 2005) to perform the CDW generation estimates for the LMA took into consideration the data obtained from three different information sources:

- the construction activity related to new building projects;
- the movement of CDW loads by collection and transportation companies;

- the monitoring of CDW discharges at illegal dumps.

Based on each of these types of information, a partial indicator for CDW generation was defined for the region as well as for the municipality of Lisbon. A partial indicator for CDW generation resulting from new building was established based on a construction activity estimate, a partial indicator for CDW generation resulting from remodeling was established based on estimates of waste load movements, and a partial indicator for CDW discharges at illegal dumps was established based on estimated discharges at illegal dumps. Following the gathering of this information, the total amount of CDW originating in the LMA was estimated (with the amount corresponding to the Lisbon municipality being shown separately), special care being taken to prevent overlap of specific aspects such as the amounts of waste discharged at illegal dumps, which were deemed to be inconsistent and were therefore separated from the first two partial indicators when the total quantity of CDW generated in the Lisbon municipality was estimated. The amount of waste discharged at illegal dumps in the LMA was also deemed to be inconsistent due to its low volume. In fact, it is highly probable that a large portion of the illegal disposal is a result of the transportation and collection agents' actions in the cities of the region and, admittedly, a large part of those estimates may already have been taken into consideration in the partial indicator based on the CDW loads moved by transportation and collection companies.

The partial indicator for newly completed buildings was obtained by multiplying the new annual average (two-year) construction area $\left(\mathrm{m}^{2}\right)$ by the CDW generation indicator $\left(\mathrm{kg} / \mathrm{m}^{2}\right)$ established for Portugal. In the present study, the indicator adopted was $158 \mathrm{~kg} / \mathrm{m}^{2}$, which was defined after an analysis of various publications based on case studies conducted in Portugal. Several literature sources present various indicators for typical CDW generation per construction area $\left(\mathrm{kg} / \mathrm{m}^{2}\right)$, but only those within the range from $122 \mathrm{~kg} / \mathrm{m}^{2}$ to $211 \mathrm{~kg} / \mathrm{m}^{2}$ were herein considered as valid (Coelho and Brito, 2008; Ruivo and Veiga, 2004; Symonds, 1999). The adoption of the $158 \mathrm{~kg} / \mathrm{m}^{2}$ indicator also represents in the present study a $0.13 \mathrm{~m}^{3} / \mathrm{m}^{2}$ ratio, which is in line with several other international studies (Solís-Guzmán et al., 2009).

The calculations made to determine the partial indicator for the CDW generated by remodeling projects were based on the amount of waste moved. It should be noted, however, that such remodeling projects, when submitted for municipality approval, are generally presented as minor interventions, which do not imply the high amount of CDW that effectively occurs. Therefore, as recommended, the study did not take into account the remodeling working area $\left(\mathrm{m}^{2}\right)$ when performing the CDW generation estimates. The remodeling working area was thus ignored in the calculation of the first indicator for new construction. However, to calculate the second indicator from CDW movements, only the information relating to remodeling CDW collection was taken into consideration. This approach of controlling the use of data and keeping it in line with the sources was used in an attempt to minimize the uncertainties in the CDW generation estimation process. Furthermore, other factors contributed to this control:

- The majority of remodeling jobs were considered in this study to be informal, license-exempt activities, this being one more reason to only make use of information based on local CDW movements. INE statistics on the occurrence of remodeling projects only consider those that have been licensed, and this is why it would not be reliable to estimate the $\mathrm{CDW}$ generation from remodeling jobs without taking into account the informal jobs that seem to substantially contribute to the total amount of CDW generated. In the urban environment under study, it is understood that the main 
Table 7

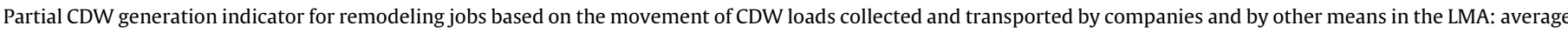
value for the two-year period from 2006 to 2007 (De Melo, 2009).

\begin{tabular}{|c|c|c|c|c|c|c|c|}
\hline \multirow[t]{4}{*}{ Geographic location } & \multicolumn{2}{|c|}{ Population 2007} & \multicolumn{5}{|c|}{ Data for remodeling projects } \\
\hline & \multirow[t]{3}{*}{ Inhab. $\left(10^{3}\right)$} & \multirow[t]{3}{*}{$\%$} & \multicolumn{3}{|c|}{ Set of partial data on CDW flows } & \multirow{2}{*}{\multicolumn{2}{|c|}{$\begin{array}{l}\text { Partial CDW } \\
\text { generation } \\
\text { indicator }\end{array}$}} \\
\hline & & & $\begin{array}{l}\text { Up to } 1 \mathrm{~m}^{3} \\
\text { collection by } \\
\text { municipalities }\end{array}$ & $\begin{array}{l}\text { Up to } 1 \mathrm{~m}^{3} \\
\text { voluntary and } \\
\text { free delivery at } \\
\text { Ecocenters }\end{array}$ & $\begin{array}{l}\text { Collected by } \\
\text { companies } \\
\text { operating in } \\
\text { the area }\end{array}$ & & \\
\hline & & & t/day & t/day & t/day & t/day & $\%$ \\
\hline LMA & 2808 & 100 & 80.98 & 28.33 & 2067 & 2176 & 100 \\
\hline Greater Lisbon & 2026 & 72 & 10.96 & 0.03 & 1722 & 1733 & 80 \\
\hline Municipality of Lisbon & 500 & 18 & 2.11 & 0.03 & 943 & 945 & 43 \\
\hline \multirow[t]{2}{*}{ Setúbal Peninsula } & 783 & 28 & 70.02 & 28.30 & 345 & 444 & 20 \\
\hline & A & $\mathrm{B}$ & $\mathrm{C}$ & $\mathrm{D}$ & $\mathrm{E}$ & $\mathrm{F}$ & G \\
\hline
\end{tabular}

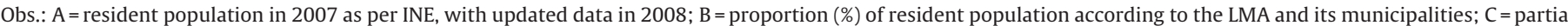

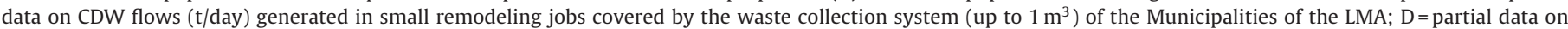

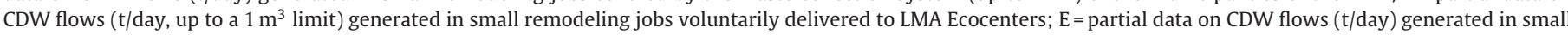

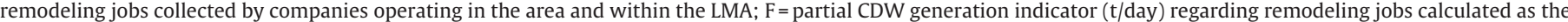
sum of the three previous columns $(F=C+D+E) ; G=$ proportion (\%) of CDW generated by remodeling jobs according to the LMA and its municipalities.

Table 8

Final CDW generation indicator in urban construction projects by geographic location: average value for the two-year period from 2006 to 2007 (De Melo, 2009).

\begin{tabular}{|c|c|c|c|c|c|c|c|}
\hline \multirow[t]{4}{*}{ Geographic location } & \multicolumn{2}{|c|}{ Population in 2007} & \multicolumn{5}{|c|}{ Data for urban construction projects } \\
\hline & \multirow[t]{3}{*}{ Inhab. $\left(10^{3}\right)$} & \multirow[t]{3}{*}{$\%$} & \multicolumn{2}{|c|}{$\begin{array}{l}\text { Sum of partial CDW generation } \\
\text { indicators }\end{array}$} & \multirow[t]{2}{*}{$\begin{array}{l}\text { Estimate of CDW collected at } \\
\text { illegal dumps }\end{array}$} & \multicolumn{2}{|c|}{$\begin{array}{l}\text { CDW generation } \\
\text { indicator }\end{array}$} \\
\hline & & & \multirow{2}{*}{$\frac{\text { New construction }}{\text { t/day }}$} & \multicolumn{3}{|l|}{ Remodeling } & \\
\hline & & & & t/day & t/day & t/day & $\%$ \\
\hline LMA & 2808 & 100 & 1427 & 2176 & 15.1 & 3619 & 100 \\
\hline Greater Lisbon & 2026 & 72 & 923 & 1733 & 5.9 & 2661 & 74 \\
\hline Municipality of Lisbon & 500 & 18 & 9 & 945 & - & 954 & 26 \\
\hline \multirow[t]{2}{*}{ Setúbal Peninsula } & 783 & 28 & 505 & 444 & 9.2 & 958 & 26 \\
\hline & A & $\mathrm{B}$ & $\mathrm{C}$ & $\mathrm{D}$ & $\mathrm{E}$ & $\mathrm{F}$ & G \\
\hline
\end{tabular}

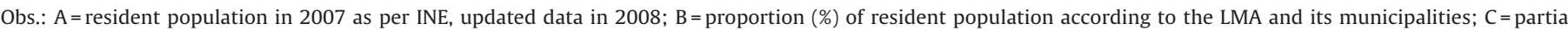

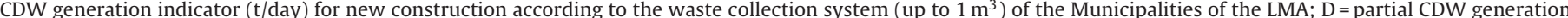

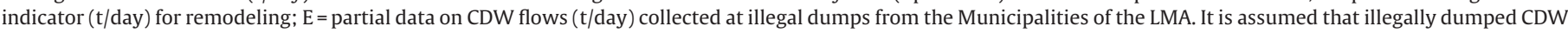

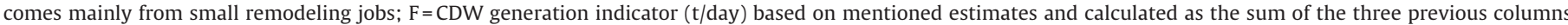
$(\mathrm{F}=\mathrm{C}+\mathrm{D}+\mathrm{E}) ; \mathrm{G}=$ proportion (\%) of CDW generation ( $\mathrm{t} /$ day) in building projects according to the LMA and its municipalities.

Table 9

CDW indicators and generation rate for urban building projects per geographic location: average value for the two-year period from 2006 to 2007 (De Melo, 2009 ).

\begin{tabular}{|c|c|c|c|c|c|c|}
\hline \multirow[t]{3}{*}{ Geographic location } & \multicolumn{2}{|c|}{ Population 2007} & \multicolumn{4}{|c|}{ Data regarding urban building projects } \\
\hline & \multirow[b]{2}{*}{ Inhab. $\left(10^{3}\right)$} & \multirow[b]{2}{*}{$\%$} & \multicolumn{2}{|c|}{ CDW generation indicators } & \multicolumn{2}{|c|}{ CDW generation rate per capita } \\
\hline & & & t/day & $\mathrm{t} /$ year $\left(10^{3}\right)$ & $\%$ & t/inhab.year \\
\hline LMA & 2808 & 100 & 3619 & 1129 & 100 & 0.40 \\
\hline Greater Lisbon & 2026 & 72 & 2661 & 830 & 74 & 0.41 \\
\hline Municipality of Lisbon & 500 & 18 & 954 & 298 & 26 & 0.60 \\
\hline \multirow[t]{2}{*}{ Setúbal Peninsula } & 783 & 28 & 958 & 299 & 26 & 0.38 \\
\hline & A & B & $\mathrm{C}$ & $\mathrm{D}$ & $\mathrm{E}$ & $\mathrm{F}$ \\
\hline
\end{tabular}

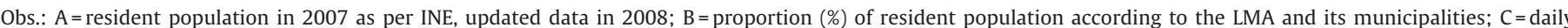

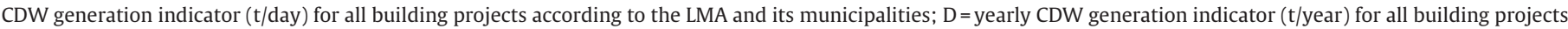

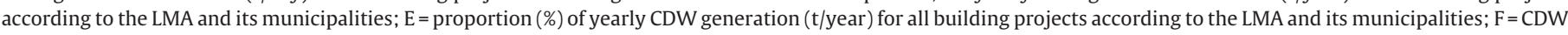
generation rate per capita ( $\mathrm{t} /$ inhab.year) resulting from estimates $(\mathrm{F}=\mathrm{D} / \mathrm{A})$.

Table 10

Comparison between CDW estimates for the municipality of Lisbon according to different studies and reference years (Godinho, 1999; De Melo, 2009).

\begin{tabular}{|c|c|c|c|c|}
\hline \multirow[t]{3}{*}{ Reference year } & \multirow{3}{*}{$\begin{array}{l}\text { Resident population } \\
\text { Inhab. }\left(10^{3}\right)\end{array}$} & \multicolumn{3}{|c|}{ CDW (estimate) } \\
\hline & & \multicolumn{2}{|c|}{ Indicators } & \multirow{2}{*}{$\begin{array}{l}\text { Per capita rate } \\
\text { t/inhab.year }\end{array}$} \\
\hline & & t/day & t/year $\left(10^{3}\right)$ & \\
\hline \multicolumn{5}{|c|}{ Municipality of Lisbon } \\
\hline Godinho (1999) & 641 & 680 & 212 & 0.33 \\
\hline De Melo (2009) & 500 & 954 & 298 & 0.60 \\
\hline Variation & $-22 \%$ & $40 \%$ & $40 \%$ & $82 \%$ \\
\hline
\end{tabular}

Obs.: CDW generation indicator ( $\mathrm{t} /$ year) calculated by taking into account $\mathrm{t} /$ day and 26 days per month. 
Table 11

Synthesis of CDW generation estimates and final destinations (both known and unknown) within the LMA: average value for the two-year period from 2006 to 2007 (De Melo, 2009).

\begin{tabular}{|c|c|c|c|}
\hline & \multicolumn{2}{|l|}{ CDW } & \multirow{2}{*}{$\begin{array}{l}\text { Geographic } \\
\text { location }\end{array}$} \\
\hline & $\mathrm{t} /$ year $\left(10^{3}\right)$ & $\%$ & \\
\hline \multirow{3}{*}{$\begin{array}{l}\text { CDW generation } \\
\text { estimate }\end{array}$} & 1129 & 100.0 & LMA \\
\hline & 830 & 73.5 & Greater Lisbon \\
\hline & 299 & 26.5 & Setúbal Peninsula \\
\hline $\begin{array}{l}\text { Unknown CDW } \\
\text { destinations }\end{array}$ & 773 & 68.4 & \\
\hline $\begin{array}{l}\text { Known CDW } \\
\text { destinations }\end{array}$ & 356 & 31.6 & \\
\hline $\begin{array}{l}\text { Landfill system (public } \\
\text { companies) }\end{array}$ & & & \\
\hline L3 e L4 & 61 & 17.0 & Setúbal Peninsula \\
\hline L2 & 4 & 1.2 & Greater Lisbon \\
\hline L1 & 0.015 & 0.0 & \\
\hline \multicolumn{4}{|l|}{$\begin{array}{l}\text { Treatment, re-use } \\
\text { and/or disposal (private } \\
\text { companies) }\end{array}$} \\
\hline $\mathrm{C} 3$ & 107 & 30.1 & Setúbal Peninsula \\
\hline $\mathrm{C} 4$ & 100 & 28.1 & \\
\hline $\mathrm{C} 1$ & 64 & 17.9 & Greater Lisbon \\
\hline $\mathrm{C} 2$ & 20 & 5.7 & \\
\hline Total & 356 & 100.0 & \\
\hline
\end{tabular}

source of CDW loads is the totality of small remodeling projects, licensed or not.

- To estimate the amount of CDW generated by the small remodeling projects, partial information (average amounts per day) obtained from three different sources was aggregated:

- average percentage declared by waste collection and transportation companies contacted about their activities related to CDW collection from small remodeling jobs, 59.8\%;

- amounts declared by the municipality as to small CDW loads (up to $1 \mathrm{~m}^{3}$ ) generated by small remodeling jobs;

- amounts declared by companies that manage ecocenters in the LMA as to waste freely and voluntarily delivered to them.

In Table 10, it can be seen that the last published estimate for CDW generated in the municipality of Lisbon in 2007 is about $40 \%$ higher than the one performed in 1997, even though the construction activity in the Greater Lisbon area had remained practically at the same level. A comparison of the data from the two years is shown in Fig. 2. The methodology adopted for the present study (2007) ought to account for the difference in the results considering the high reliability of the data and information used to calculate the resulting estimates. It is important to note that in both studies, the calculations made to determine the CDW estimates did not take into account soil-type excavation waste.

\subsection{Monitoring the final destinations of CDW within the $L M A$}

Table 11 presents systematized data regarding the known final destinations of CDW within the LMA, which are broken down into two groups: landfill system and treatment companies versus reuse and disposal companies. Special mention must be made of the fact that only $31.6 \%$ of the CDW generated in the LMA had a known destination. Of note is also the low amount of CDW identified as having company "L1" as its final destination. Another interesting aspect is the fact that the sub-region generating the most CDW (Greater Lisbon, CDW origin $=73.5 \%$ ) is equipped with the smallest infrastructure for the final destination of its waste (Greater Lisbon, CDW destination $=24.8 \%$ ). Therefore, this means that the Setúbal
Table 12

Destination/treatment adopted for CDW delivered to private treatment, re-use and disposal companies within the LMA: average value for the two-year period from 2006 to 2007 (De Melo, 2009).

\begin{tabular}{lrr} 
& \multicolumn{2}{l}{ CDW } \\
& LMA & \\
\cline { 2 - 3 } & t/year $\left(10^{3}\right)$ & $\%$ \\
\hline CDW generation estimate & 1129 & \\
Known CDW destinations & 356 & 31.6 \\
CDW delivered to private treatment, & 292 & 100.0 \\
re-use and/or disposal companies & & \\
Company & 14 & 7.7 \\
$\quad$ Improvement of recycled aggregates & 230 & 2.7 \\
Landfill disposal & 8 & 12.3 \\
Sanitary landfill disposal & 36 & 1.4 \\
$\quad$ Redirecting them to other waste & & \\
treatment and re-use companies & 4 & \\
$\quad$ Other & & \\
\hline
\end{tabular}

Peninsula has been the final destination for a significant portion of the CDW generated in the LMA, especially for that generated in the municipality of Lisbon.

Table 12 identifies the types of destinations adopted for CDW as treatment, re-use and/or disposal companies. In this case, only $4.7 \%$ of CDW is used for improving recycled aggregates, this being mostly performed by companies. In contrast, landfill disposal is the final destination of $78.9 \%$ of the CDW delivered to companies.

Fig. 4 presents the locations of this infrastructure. This figure also shows that all identified facilities are located at a maximum distance of approximately $23 \mathrm{~km}$ from Marquês de Pombal Plaza in Lisbon (the municipality with the highest CDW generation estimate). This location distribution seems to favor the municipality of Lisbon due to the likely reduction of costs related to CDW transportation within the path source/destination. However, this distribution has not prevented illegal dumps from occurring, as confirmed by the Municipality. Fig. 4 also depicts the suboptimal location of the sole ecocenter (E1), which is situated almost at the boundary between Lisbon and Odivelas. The small amount of CDW delivered to this ecocenter may be due to its location.

\subsection{Composition of CDW in Lisbon}

To characterize the CDW generated in the municipality of Lisbon, a comparison was made between the average composition identified in the records of Public Works Construction/Waste Treatment, valuation and disposal Companies derived from data gathered for 2007 and the average CDW composition identified in another study performed for 1997 (Godinho, 1999). Notwithstanding the 10-year difference between the two datasets, the results show great similarity. Both reference years show little waste corresponding to packaging and copious waste (97\% and 98\%) corresponding to materials such as concrete, bricks, tiles, wood, glass, plastics, iron and steel. Excluded from this waste composition is the amount of soil originating from excavation projects. Moreover, much of it (approximately 50\%) corresponds to a mixture of concrete and ceramic waste (bricks, tiles).

\subsection{Comparison with other municipalities}

Estimates for CDW generated in other urban environments (including Lisbon PT) based on the same methodology described in this work are presented in Table 13. The three information sources used to perform the partial CDW estimates (partial indicators for new building construction, remodeling projects and illegal disposal) make it possible to differentiate the origin of the waste in accordance with the type of work and its prevalence in each urban environment. The amount of CDW generated by new building con- 


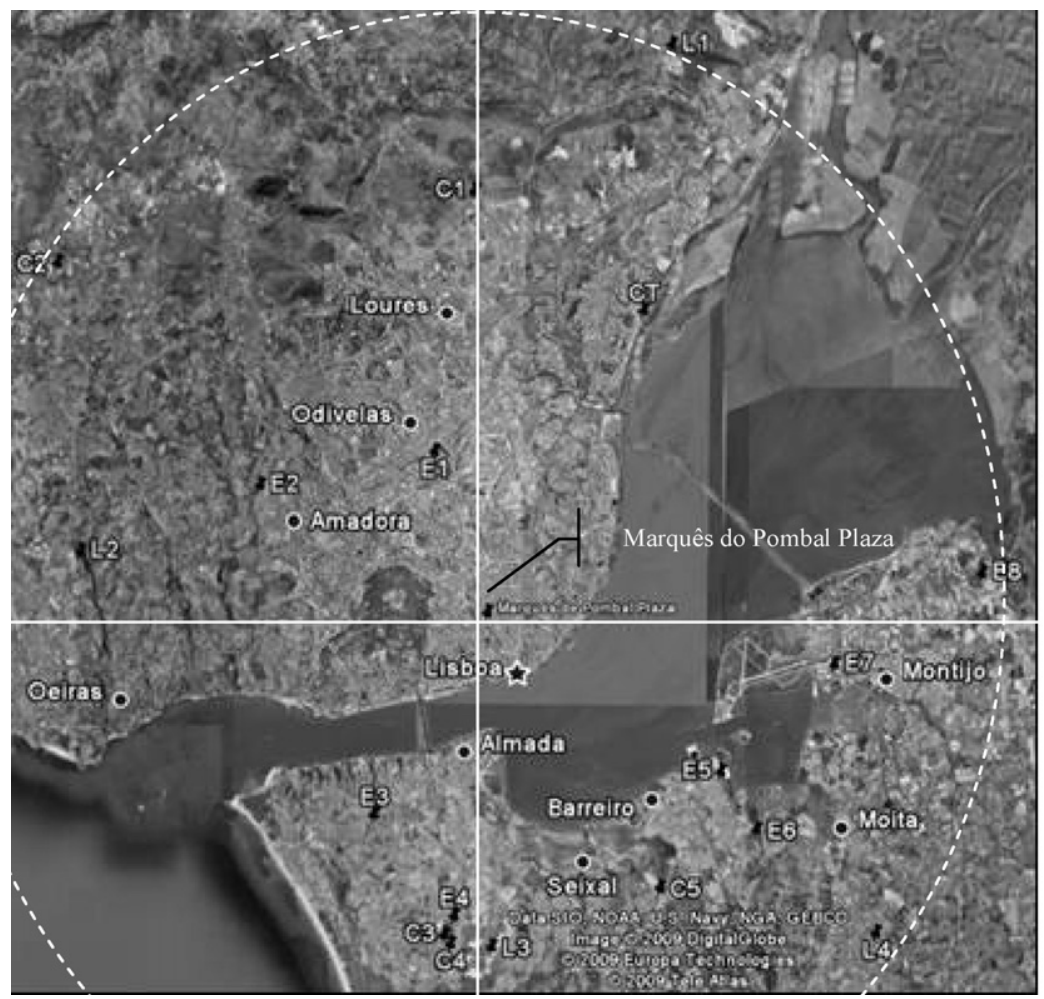

Legend:

L - Sanitary landfill;

E- Ecocenters;

CT - Solid waste treatment centers;

C - CDW treatment companies

Fig. 4. Location of the infrastructure designed to receive CDW generated in the LMA (De Melo, 2009)

Table 13

Comparison between CDW generated in several Brazilian municipalities and in the municipality of Lisbon (De Melo, 2009; Pinto and González, 2005).

\begin{tabular}{|c|c|c|c|c|c|c|c|}
\hline \multirow[t]{2}{*}{ Municipality } & \multirow{2}{*}{$\begin{array}{l}\text { Population } \\
\text { Inhab. }\left(10^{3}\right)\end{array}$} & \multirow{2}{*}{$\begin{array}{l}\text { CDW from new } \\
\text { construction } \\
\text { t/day }\end{array}$} & \multirow{2}{*}{$\begin{array}{l}\text { CDW from Remodeling } \\
\text { t/day }\end{array}$} & \multirow{2}{*}{$\begin{array}{l}\text { Inappropriately } \\
\text { deposited CDW } \\
\text { t/day }\end{array}$} & \multirow{2}{*}{$\begin{array}{l}\text { Total CDW } \\
\text { t/day }\end{array}$} & \multicolumn{2}{|c|}{ CDW per capita } \\
\hline & & & & & & t/hab.year & Data for year \\
\hline São José dos Campos & 539 & 201 & 184 & 348 & 733 & $0.47^{c}$ & 1995 \\
\hline Ribeirão Preto & 505 & 577 & 356 & 110 & 1043 & $0.71^{\mathrm{c}}$ & 1995 \\
\hline Santo André & 649 & 477 & 536 & - & 1013 & $0.51^{\mathrm{c}}$ & 1997 \\
\hline Uberlândia & 501 & 359 & 359 & 241 & 958 & $0.68^{c}$ & 2000 \\
\hline Guarulhos & 1073 & 576 & 732 & - & 1308 & $0.38^{\mathrm{c}}$ & 2001 \\
\hline Recife & $1487^{a}$ & 430 & 263 & 680 & 1372 & $0.29^{d}$ & 2004 \\
\hline Lisbon & $500^{\mathrm{b}}$ & 9 & 945 & - & 954 & $0.60^{\mathrm{d}}$ & 2007 \\
\hline
\end{tabular}

a IBGE (Instituto Brasileiro de Geografia e Estatística - Brazilian Institute of Geography and Statistical data), (IBGE, 2004).

b INE (Instituto Nacional de Estatística - National Institute for Statistical Data), (INE, 2007).

c Pinto and González (2005)

d De Melo (2009)

struction in the case of Recife and the other Brazilian municipalities is compatible with urban environment that prevails during a city's formation and expansion period. In the case of the Lisbon municipality, the amount of CDW generated by building remodeling is rather large and compatible with a mature urban environment that requires building rehabilitation.

It is also generally verified that when data referring to illegal CDW disposals are not included due to its inconsistency, the values of the other two partial indicators tend to be high, revealing that a great deal of the illegal disposal carried out by agents involved in waste collection and transportation has already been taken into account. Therefore, the estimates for total CDW generation seem in all cases to be reliable, considering that by aggregating the partial indicators, overlapping of the estimates is avoided.

The observed per capita CDW generation rates (Table 13) vary between 0.29 (Recife) and 0.71 (Ribeirão Preto) in line with the size of each urban environment under consideration, i.e., the values tend to be lower whenever the municipality's population is higher. Moreover, the per capita CDW generation rate found for Lisbon is compatible with this correlation.

\section{Conclusions}

The methodology used has proven to be effective for preparing CDW generation estimates per project type, and it shows the significant presence of CDW in the studied region (the LMA) and particularly in the municipality of Lisbon. The data suggest an intensive degree of CDW generation, and it confirms the transformation in urban environments of large amounts of raw material into waste. In fact, the municipality of Lisbon does not seem to be properly equipped to cope with such a significant volume of CDW coming from small remodeling projects, which is the prevailing type of work in the city.

The extent of the environmental problems caused by CDW in the municipality of Lisbon can be characterized as follows:

1. the main indicator and the per capita rate for CDW generation in Lisbon are (respectively) $954 \mathrm{t} /$ day and $0.60 \mathrm{t} /$ inhab.year. Both values are above the average for the LMA and its two sub-regions (Greater Lisbon and the Setúbal Peninsula); 
2. the municipality of Lisbon has a defective infrastructure for coping with the substantial amount of CDW generated, and as expected, part of the waste is illegally dumped within the urban network and/or its outskirts. The destination of most of this waste, which is transported by companies operating in the area, is the Setúbal Peninsula, which is a sub-region that generates less CDW;

3. authorized CDW destinations identified in the LMA are situated within a maximum distance of about $23 \mathrm{~km}$ from Marquês do Pombal Plaza, which is approximately the geometric center of the city of Lisbon. Despite the fact that these locations favor the municipality of Lisbon due to the likely reduction in costs associated with CDW transportation, in terms of the origin/destination path, the occurrence of illegal dumps is still a reality;

4. to collect CDW up to $1 \mathrm{~m}^{3}$ from small remodeling jobs within the municipality of Lisbon, there is only one ecocenter (E1) that it is suboptimally located in the urban network, and collection service (by the Municipality) upon request from inhabitants has not been efficient;

5. furthermore, municipal managers have shown a lack of initiative in implementing effective management solutions for CDW generated in the city, likely because Decree-Law Nr. 46/2008 does not clearly define the responsibilities of Municipalities in this process.

In overall terms, special reference is made to the active participation of the private sector (transportation, reception and treatment agents), which sees CDW management activities within the LMA as a business opportunity. Of note are ongoing activities, mainly in terms of private initiatives, with the goals of training CDW management and of adjusting the actions of agents involved in the recent Decree-Law Nr. 46/2008, 12 March.

Regarding inspections of the agents involved as an important management instrument, it is recommended that they should be conducted as a complement to the provision of facilities and as a specific solution to problems related to the adequate management of CDW. Thus, once conditions are created for proper waste management by the public administration and by the private agents involved, a thorough inspection must be carried out with the goal of duly transferring the present situation to the new management system in the first stage, and in the second stage of ensuring the full implementation of the actions to be performed.

Lastly, because CDW generation is inevitable in urban environments during the consolidation of cities, during periods of population expansion (as in the case of the neighboring municipalities of Lisbon and Brazilian municipalities), and during periods of maturity with the need to renew buildings (as in the case of the municipality of Lisbon), permanent efforts are required to achieve more judicious management of CDW. Hence, within this continuously and gradually evolving process, a few actions are considered to be relevant, such as the implementation of means intended to facilitate authorized disposal (a CDW collection system within the urban network) and the full differentiation of collected waste. These actions are to be integrated within a group of other actions ultimately intended to minimize waste generation, to extend the responsibilities of the agents involved and to develop recycling as an economic activity. Meanwhile, because a consolidated market for recycled CDW aggregates does not yet exist, this latter process must be the result of gradual advances, and therefore new CDW landfills that properly preserve the aggregate part of waste (clean materials) should be installed with a view to eventual recycling.

\section{Acknowledgements}

The authors are very grateful to all the agents involved in the generation, transportation and reception of CDW in the metropoli- tan area of Lisbon for their helpful collaboration in answering the questionnaires. We also wish to thank the National Laboratory for Civil Engineering (LNEC) for the support provided by it, which allowed studies in Lisbon. Finally, the first author would like to thank the CAPES (Coordenação de Aperfeiçoamento de Pessoal de Nivel Superior), the organization from Brazil that provided the financial support for the development of this research.

\section{References}

Carvalho Pedro. Construction waste management, MSc dissertation. College of Civil Engineering, of Technical University of Lisbon, Lisbon, Portugal; 2009 [in Portuguese].

Coelho A, Brito J. Estimation of CDW generation in Portugal. In: Presentation course apply new requirements in the CDW management, FUNDEC/DECivil/IST; 2008 [in Portuguese].

De Melo AB. Construction and demolition waste management: comparative study Brazil-Portugal. In: Report on National Laboratory for Civil Engineering - LNEC, Lisbon, Portugal; 2009 [in Portuguese].

Decree-Law Nr. 178/2006, 5 September. General system of waste management ministry of environment, spatial planning and regional development. Republic Journal, I Series-A - Nr. 171 - Lisbon, Portugal; 2006 [in Portuguese].

Decree-Law Nr. 46/2008, 12 March. The system of construction and demolition waste management - ministry of environment, spatial planning and regional development. Republic Journal, I Series-A - Nr. 51 - Lisbon, Portugal; 2008 [in Portuguese]

Duran X, Lenihan H, O'Regan B. A model for assessing the economic viability of construction and demolition waste recycling - the case of Ireland. Resources. Conservation and Recycling 2006;46(3):302-20.

Ekanayake LL, Ofori G. Building waste assessment score: design-based tool. Building and Environment 2004;39(7):851-61.

Godinho Rui. Construction and demolition waste management in Lisbon. In: 2nd International technical conferences waste, Lisbon, Portugal; 1999 (in Portuguese).

IBGE - Brazilian Institute of Geography and Statistical data. Population estimateyear 2004. Rio de Janeiro, Brazil; 2004. http://www.ibge.gov.br/home.[accessed on:05/08/2008].

INE. National Institute for Statistical Data. Inhabitant statistical data-year 2007. Lisbon, Portugal; 2007. http://www.ine.pt [accessed on: 23/05/2008]. [in Portuguese].

INE - National Institute for Statistical data. Statistics for finished works. Updated data for 08/07/2008. Lisbon, Portugal; 2008. http://www.ine.pt [accessed on: 25/07/2008]. [in Portuguese].

LNEC. National Laboratory for Civil Engineering - E 471-2006 - Guide for the use of recycled coarse aggregates in hydraulic binder concrete, Lisbon, Portugal; 2006a [in Portuguese].

LNEC. National Laboratory for Civil Engineering - E 472-2006 - Guide for the production of recycled hot mix asphalt, Lisbon, Portugal, 2006b [in Portuguese].

LNEC. National Laboratory for Civil Engineering - E 473-2006 - Guide for the use of recycled aggregates in unbound pavement layers, Lisbon, Portugal, 2006c [in Portuguese].

LNEC. National Laboratory for Civil Engineering - E 474-2006 - Guide for the use of construction and demolition waste in embankments and in base courses of transportation infra-structures, Lisbon, Portugal, 2006d [in Portuguese].

Nunes KRA, Mahler CF, Valle R, Neves C. Evaluation of investments in recycling centers for construction and demolition wastes in Brazilian municipalities. Waste Management 2007;27(11):1531-40.

Pereira L, Jalali S, Aguiar JLB. Construction and demolition waste management. In: Workshop integrated management systems for specific waste streams; 2004 [in Portuguese]

Pinto TP, González JLR. In: Construction waste handling and management - guidance manual: how to deploy a system for handling and management in municipalities, vol. 1; 2005 [in Portuguese].

Pinto TP. Methodology for management of urban construction solid waste. Thesis (PhD) - polytechnic School of University of São Paulo, São Paulo, Brazil; 1999. 189 p. [in Portuguese].

Project REAGIR. Life03 ENV/P/000506. CDW recycling in the context integrated management waste. Report with presentation results; 2008. Available from: http://www.cm-montemornovo.pt/reagir/ [access 01.12.2008] Portugal [in Portuguese].

Project WAMBUCO. European Waste Manual for above ground construction (Translation by Jalali S, Perreira L.), vols. I and III. Portugal; 2005 [in Portuguese].

Rodriguez G, Alegre FJ, Martinez G. The contribution of environmental management systems to the management of construction and demolition waste: the case of the Autonomous Community of Madrid (Spain). Resources, Conservation and Recycling 2007;50(3):334-49.

Ruivo, Veiga. Construction and demolition waste: strategy for a management model. In: Study of course degree in environmental engineering. Portugal: Technical University of Lisbon; 2004 [in Portuguese].

Salinas L. Construction and demolition waste management. Contribution to the assessment and management of municipal construction waste in Portugal, MSc dissertation in College of Civil Engineering, Technology University of Coimbra, Portugal; 2002 [in Portuguese]. 
Santos AR, Jalali S. Proposed methodology for prediction of construction waste application to Vale of Ave municipalities. In: 9th National environmental conference, vol. 3. Portugal: University of Aveiro; 2007. p. 1018 [in Portuguese].

Silva JFF, Sousa RJV. Characterization and quantification of benefits and costs to support integrated management plans for construction and demolition waste. In: 2nd National meeting of municipal engineering and management (ENEGM). Porto, Portugal: Centre for Energy and Technology; 2005a [in Portuguese].

Silva JFF, Sousa RJV. Regional plan for construction and demolition waste integrated management: the first step to solving environmental problems and material recovery. In: 2nd National meeting of municipal engineering and management (ENEGM). Centre for Energy and Technology; 2005b [in Portuguese].

Solís-Guzmán J, Marrero M, Montes-Delgado MV, Ramírez-de-Arellano A. A Spanish model for quantification and management of construction waste. Elsevier Ltd. Journal of Waste Management 2009;29:2542-8.

Symonds, Group Ltd. Construction and demolition waste management practices and their economic impact. Report to DGXI, European Commission; 1999. Available from: http://ec.europa.eu/environment/waste/studies/cdw/cdw_chapter16.pdf. 